\title{
The Design and Research on Automatic Packaging Machine of the Strains
}

\author{
Qiuxiao Yang ${ }^{\text {a }}$, Kaibao Wang ${ }^{\text {b }}$, Mingzhu Zhang ${ }^{\mathrm{c}}$, Li Zhao ${ }^{\mathrm{d}}$, \\ Su Hang and Ming Meng
}

College of Mechanical Engineering, Beihua University, Jilin 132021, China

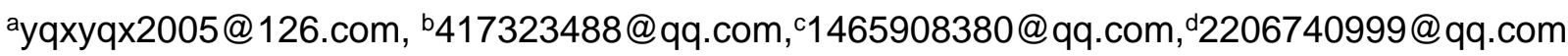

\begin{abstract}
The strains packaging is mainly completed by hand in mushroom planting industry. In order to improve the low efficiency, an automatic packaging machine of the strains was designed. The machine involves the auger delivery, heat-sealing and cutting mechanism. Theoretical calculation and numerical simulation was applied for the auger delivery unit. This packaging machine can meet the demand of the relative technical requirements, and suitable for promotion in the medium and small farmers.
\end{abstract}

Keywords: Heat seal; automatic packaging; the mushroom strains.

\section{Introduction}

Chinese packaging industry begin to grow in the 1980s. There was a scanty few of mushroom strains packaging machine applied in China, and lower efficiency than developed countries due to the lower starting point and smaller scale. Improving the degree of automation is the main tendency for the development of the packaging industry in the world $[1,2]$. So the design of mushroom strains packaging machine is presented.

\section{Principle scheme design for heat-sealing and cutting mechanism}

Sealing strength and the integrated seal of plastic packaging bag are always the quality control elements in the production of packaging products [3]. There are various measures used for heat-sealing, such as the principle of high-frequency electric field, hot plate and infrared radiation, different heat-sealing methods should be used for different materials. As shown in Figure 1, the heat sealing mechanism of this research accomplish the packaging procedure though the cutting methods of vertical sealing of rotary roller as shown in Figure 1(a) and horizontal sealing of rolling cutter as shown in Figure 1(b).

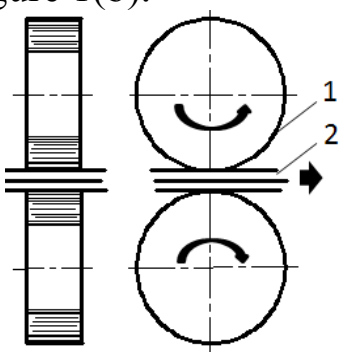

(a) Vertical sealing of rotary roller

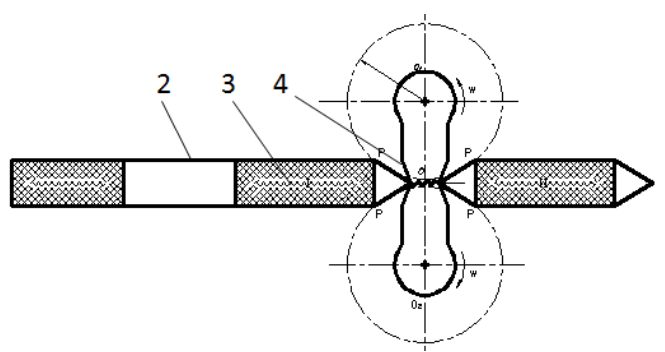

(b) Horizontal sealing of rolling cutter

Fig. 1 The principle diagram of the heat-sealing

1. Longitudinal sealing roller. 2. Membrane. 3. Strain 4 roll cutting tool.

\section{The structure design of the automatic packaging machine of the strain}

\subsection{The design of the massive structure}

The automatic packaging machine of strain used modularized design methods [4], including power source, unit of stockpile and feed, unit of gyratory compaction, unit of packaging and cutting, unit of thermoplastic seal, As shown in Figure 2, the incompact strains were fed into the storage vat, 
the packaging procedure will be achieved through automatic discharge, automatic compaction, automatic packaging, automatic cutting, automatic thermoplastic and so on.

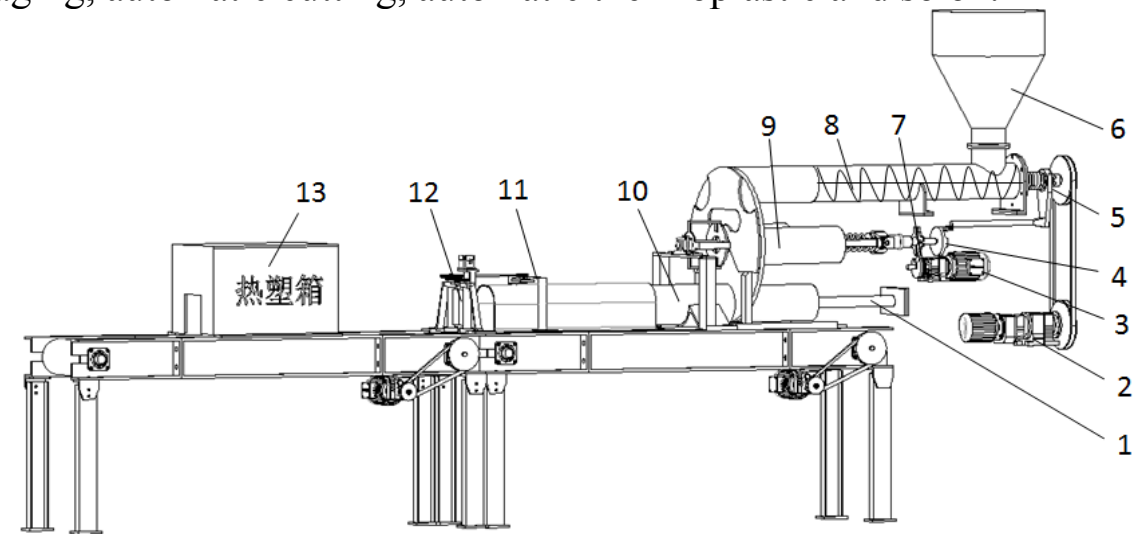

Fig. 2 The systematic diagram of the automatic packaging machine of the strain

1. Pestle. 2. Feeding motor. 3. Dividing motor. 4. Cam mechanism. 5. Clutch. 6. Storage vat. 7. Geneva mechanism. 8. The axle of auger delivery. 9. Rotary charging barrel. 10. Discharging vat. 11.

The roller of vertical sealing. 12. Rolling cutter. 13. The box of thermoplastic.

Packaging machine's working procedure as followed. Feeding motor 2 drives the axle of auger delivery 8 to rotate though belt driving. The strains which in the storage vat 6 are pushed into rotary charging barrel 9 at high speed, and this will meet the requirements of compactness of the strains.

Dividing motor 3 drives rotary charging barrel 9 intermittent rotation though geneva mechanism 7 , pestle 1 push the strains fall into the thermoplastic packaging membrane directly though discharging vat 10 , belt conveyor transports the strains forward, the roller of vertical sealing 11 seals the two sides of the plastic membrane to form cylinder shape. Rolling cutter 12 seals and cuts every part of the strains. Finally, the box of thermoplastic 13 heats the membrane so that shrink and fasten strains.

\subsection{The design of the gyratory compaction unit}

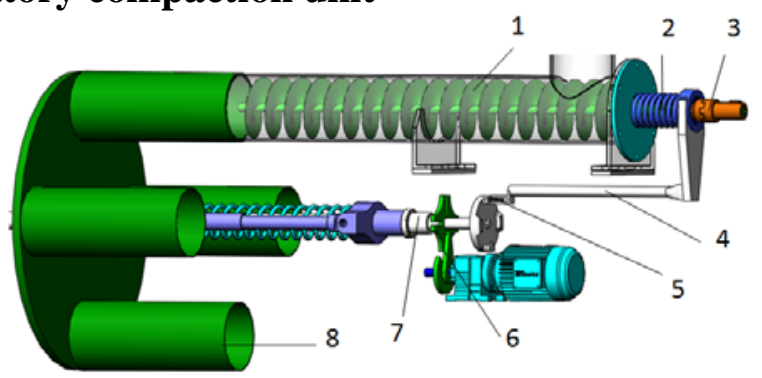

Fig. 3 The principle diagram of the gyratory compaction unit

1. Helical runner. 2. Spring. 3. Mechanical clutch. 4. Linkage. 5. Cam. 6. Geneva mechanism.7.Spline shaft. 8. Charging barrel

The unit of the gyratory compaction as shown in figure 3. Geneva mechanism 6 cooperate with cam mechanism, when geneva mechanism 6 drives the rotation of charging barrel 8 , cam mechanism 5 was located in low position, spring 2 separates clutch 3 , the axle of auger delivery 1 stop feeding the material, after the charging barrel 8 turns $90^{\circ}$, cam mechanism changed its position from low position to high position and closed the clutch 3 though pushing the linkage 4, the axle of auger delivery start rotating and feed the material to next charging barrel 8 . So, the automatic packaging work can be achieved.

\section{Theoretical analysis and computation}

Supposing the force of strain $\mathrm{M}$ acted by helical runner, because of the friction between strain and runner. The force $\mathrm{F}$ deviated $\beta$ angle with the normal direction of the helical surface [5]. The force $\mathrm{F}$ was divided into F1 of the normal component and F2 of the radial direction, as shown in Figure 4. 


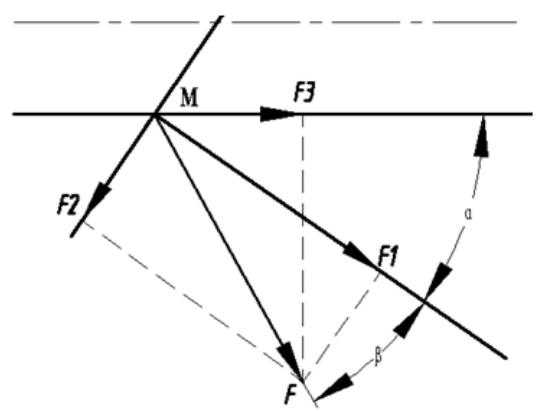

Fig. 4 The stress analysis diagram of strains

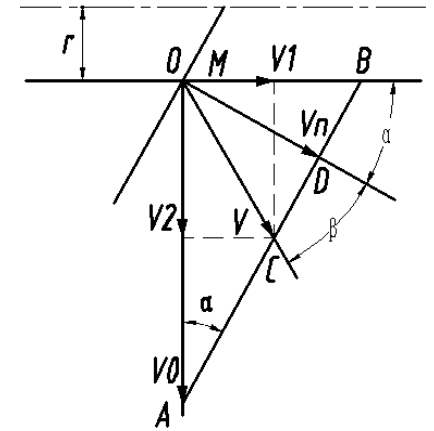

fig. 5 Motion diagram of strains

Point $\mathrm{O}$, strains $\mathrm{M}$ did composite movement which consists of axially translating and radial rotation in the trough with the speed $\mathrm{V}$ under the action of the force $\mathrm{F}$, as shown in figure 5 , the absolute motion $\mathrm{V}_{\mathrm{n}}$ of strains $\mathrm{M}$ along the normal direction of helicoid. $\mathrm{V}_{0}$ was the linear velocity of $\mathrm{M}$ in position $\mathrm{O}$. In $\triangle \mathrm{MAB}, \mathrm{V}_{\mathrm{n}}=\mathrm{V}_{0} \sin \alpha$, and in $\triangle \mathrm{ACD}, \mathrm{V}_{\mathrm{n}}=\mathrm{V}_{0} \cos \beta$, because of $\mathrm{V}_{\mathrm{n}}=2 \pi \mathrm{nr} / 60$, so $\mathrm{V}=$ $(2 \pi \mathrm{nr} \sin \alpha) /(60 \cos \beta)$, and because of $\mathrm{V}_{1}=\mathrm{V} \cos (\alpha+\beta)$, so

$$
V_{1}=\frac{2 \pi n r}{60} \sin \alpha\left(\cos \alpha-\sin \alpha \frac{\sin \beta}{\cos \beta}\right)
$$

Because of $\tan \alpha=\mathrm{S} /(2 \pi \mathrm{r}), \tan \beta=\mu$, whereby, $\mathrm{S}$ as the screw pitch, $\mu$ as the frictional coefficient between strains and helicoid. So

$$
V_{1}=\frac{2 \pi n r}{60} \sin \alpha(\cos \alpha-\mu \sin \alpha)
$$

According to trigonometric function, we can get

$$
V_{1}=\frac{S n}{60} \times \frac{1-\mu \frac{S}{2 \pi r}}{1+\left(\frac{S}{2 \pi r}\right)^{2}}=\frac{S n(2 \pi r-\mu S)}{30\left(4 \pi r^{2}+S^{2}\right)}
$$

Seen from the formula (1), when the set value of the rotate speed was constant, the speed along the axial was relative with the radius and screw pitch, so the way to choose suitable helical runner to meet the requirements of strains' compactness were depend on the radius and screw pitch.

\section{Simulation analysis}

By using the simulation model of Solidworks software to make simulation for helical runner, added fixed constraint at feed side, and added the positive pres-sure of the strains at the blade surface, the stress distribution and deformation cloud charts are obtained by simulation analysis, as shown in figure 6 and 7. The cloud chart shown that torsion stress gets smaller from the feed side to the discharge side for central axis, so the torsional deformation gets smaller. The compressive stress gets smaller from root to edge of helical blade.

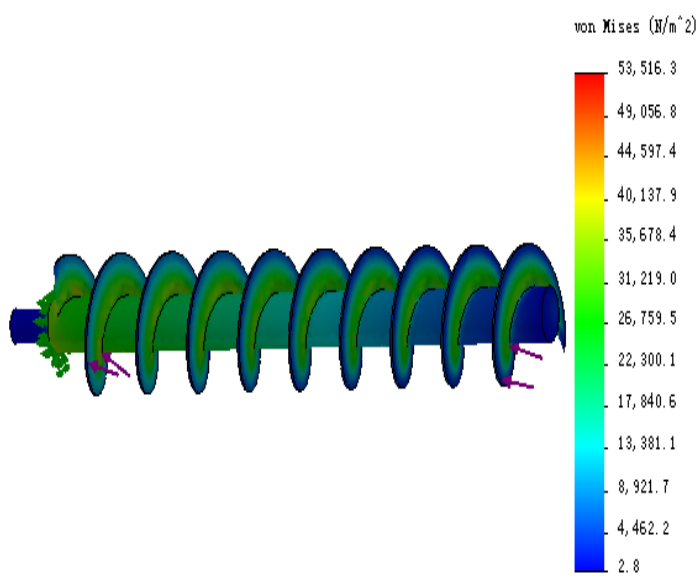

Fig. 6 The stress distribution cloud chart 


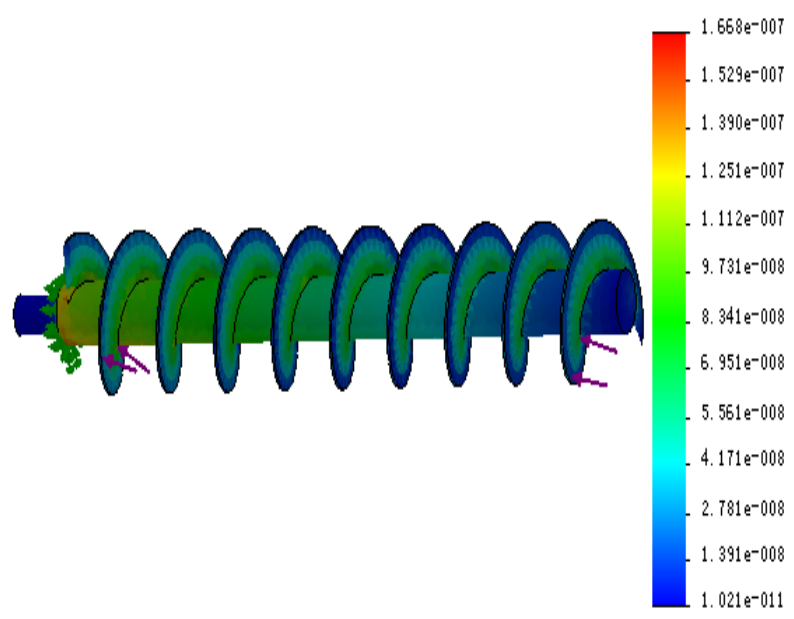

Fig. 7 The deformation cloud chart

Because the positive pressure was identified by pitch, speed, helical angle, and the kind of strain, etc. So, the suitable parameter was selected of helical runner for work efficiency, quality and working life [6].

\section{Conclusion}

In accordance with the needs of farmers, designed an automatic packaging machine of strain by using the modularized design methods based on the principle of the thermoplastic. Structural design for Rotating compaction unit, theoretical calculation and simulated analysis for the device of auger delivery. Indicate that this automatic packaging machine can meets the need of various strains by using difference contrivable parameters.

\section{References}

[1] Z. H. Wu: Accelerate the Development of the Mechanization of the Production of Edible Fungi to Promote the Transformation and Upgrading of the Leading Industry [J]. Modern Agricultural Machinery, Vol. 04 (2012).

[2] W. B. Lei: Research on the Development of Packaging Machinery Industry in China [J]. China Packaging Industry, Vol. 04 (2015).

[3] H. J. Zhang, G. Q. Zhang and C. Q. Wang: Failure Mode Analysis of Heat Sealing Strength of Plastic Packaging Bag [J]. Packaging Journal, Vol. 07 (2015).

[4] N. P. Jia: Research on the Practical Application of the Component and Modular Machine Design in the Automation Technology [J]. Science and Technology, Vol. 07 (2015).

[5] F. Yang, L. Zhao: Dynamic and Finite Element Fatigue Analysis on Screw Conveyor [J]. Coal Mine Machinery, Vol. 12 (2014).

[6] Roberts Alan W. Bulk solids: Optimizing Screw Conveyors [J]. Chemical Engineering, Vol. 02 (2015). 